\title{
Index approach implementation mechanism to the human capital assessing within the framework of the sustainable development concept
}

\author{
AlexeyShinkevich ${ }^{1}[0000-0002-1881-4630]$, Regina Yakunina $^{1 *}{ }^{[0000-0001-5467-9846]}$ and \\ TatyanaKlimenko ${ }^{1}$ [0000-0001-9832-1619] \\ ${ }^{1}$ Kazan National Research Technological University, 420015, K. Marks st., Kazan, Russia
}

\begin{abstract}
The article presents and describes the methodology for assessing human capital level using the human development index. The assessment was carried out on the example of the regions of the Russian Federation within the framework of the sustainable development concept. The priority goals of sustainable development related to human capital have been identified. The methodology for calculating the human development index is described, taking into account the characteristics of a particular country and its regions. All components of the final human development index are considered in detail. Its indicators are analyzed on the example of the Russian Federation regions. The final stage was the compilation of a rating of the Russian Federation regions according to the human development index, strong and weak regions were identified. The advantages and disadvantages of this index approach are described and how this approach is adapted to the conditions of a particular country.

Keywords: human capital, human development, human development index, sustainable development, human capital value, human capital within the framework of the sustainable development concept.
\end{abstract}

\section{Introduction}

Currently, the concept of sustainable development is one of the most relevant and presupposes such a development in which current activities and meeting the needs of modern society do not harm future generations, but finds a balance between them. In the paradigm of sustainable development, the role of realizing human potential is very important. Within the framework of our study, the priority goals of the sustainable development concept, according to the UN, are Goal 3 «Ensuring healthy lifestyles and promoting well-being for all at all ages» and Goal 4 «Ensuring inclusive and equitable quality education and promoting lifelong learning opportunities for all».

Human capital plays a leading role in the transition to sustainable development. Human capital is defined as the totality of the education capital, health capital, and also includes the

\footnotetext{
* Corresponding author: ya.rp@list.ru
} 
knowledge, skills and experience that are necessary for the implementation of professional activities in order to generate income.

In the Russian context, special attention is paid to sustainable development goals in the framework of the Human Development Report of the Russian Federation, which is annually issued by the Analytical Center under the Government of the Russian Federation.The intention of the Human Development Report for the Russian Federation is to make a brief analysis and adapt the main priorities of the UN SDGs for 2015-2030 to the Russian realities and prospects [1].

The United Nations Development Program and the World Bank are reflected in the concept of sustainable development. Within the framework of digital transformation $\mathrm{T}$. V. Malysheva, M. A. Suchkov, S. A. Bashkirtseva in their research consider the management of sustainable economic development [2]. A. A. Lubnina, A. I. Shinkevich, A. A. Shabunova and G. V. Leonidova [3] define the innovative forms of organization of production within the framework of sustainable development. The main idea of sustainable development is analyzed in detail in the work of P. Dasgupta [4]. A lot of studies of foreign and Russian researchers are devoted to the implementation of human capital within the framework of the sustainable development concept. So, A Di Fabio, JM Peiró (2018) in their work developed a new integrated leadership framework for sustainable human capital development [5].The group of researchers A. I. Shinkevich, E. L. Vodolazhskaya, J. A. Abutalipova, R. P. Yakunina, F. F. Galimulina, Ch. A. Misbachova [6] consider the directions of development of innovative human capital of industrial enterprises based on the development of an improved assessment methodology. N. M. Baranova, L. V. Sorokin analyze the effect of human capital on the sustainable development of the economy [7]. The mechanism for improving human capital within the framework of the concept of sustainable development, through the transformation of capital in the market of information services in the regional economy and advanced training of personnel of organizations is considered in the works of authors' collectives under the leadership of A. I. Romanova [8, $9,10]$.

Also, the main database of our research is Human Development Reports (2015-2018) by UNDP [11], Human Capital Project by The World Bank [12] and we use its statistical data.

The main aim of this article is to apply and implement the index approach to assessing human capital within the framework of the sustainable development concept. At the heart of index approach, we apply and test the human development index on the example of the regions of the Russian Federation. To achieve the set goal of this study, a sufficient number of scientific tools are used. In order to identify patterns and analyze the state of the identified problem, we used methods of cause-effect relationships, methods of formalization and description. From theoretical research methods, analysis and synthesis, comparative analysis is applied; such economic methods as index and graphical, as well as empirical methods of collecting and processing information are also applied. The main information base was the data of the Federal State Statistics Service, as well as the Unified Interdepartmental Information and Statistical System.

\section{Materials and methods}

In this article we will consider a number of basic issues related to the measurement of human capital among the regions of the Russian Federation within the framework of the concept of sustainable development. It is known that the most accessible and universal method for assessing human capital is the approach based on the calculation of the human development index. Therefore, in this article, we will determine the methodology for calculating the human development index and independently assess the level of human 
capital in the regions of the Russian Federation using statistical and economic methods of socio-economic research.

The Human Development Index (HDI) received the greatest value for the comparative intercountry and interregional analysis of the state of the human capital level [13]. The HDI includes quantitative parameters of human capital, and also measures the level of development, human achievement in the countries of the world and their regions.

In our study, we tried to independently calculate the HDI with a view to its further modernization in regional socio-economic systems.We know thatHDI includes three subindexes:

- life expectancy index;

- income index;

- education index.

In order to calculate the HDI among the regions, we made some adjustments in the methodology. When calculating the income index for each analyzed constituent entity of the Russian Federation, GRP per capita is used instead of per capita GDP in PPP in US dollars. In addition, we present the trends in the HDI for the regions of the Russian Federation from 2010 to 2018 in the form of its dynamics. The other two indicators, the education index and life expectancy index, are calculated by analogy with the UNDP methodology used until 2010, since the second method of calculation that is currently relevant, cannot be applied at the regional level due to insufficient statistical data.

\section{Results and discussion}

80 constituent entities of the Russian Federation were selected as objects for analysis, of which 46 regions, 21 republics, 9 territories, 1 autonomous region, 1 autonomous area, as well as Moscow and St. Petersburg. The regions of the Russian Federation were selected according to the criterion of the availability of statistical data for the period under review. To build the HDI, the following components were used as a basis:

- gross regional product (GRP) per capita by constituent entities of the Russian Federation at current basic prices;

- life expectancy (number of years);

- adult literacy rate during the period;

- the proportion of students among people aged 7 to 24 years.

Next, we will analyze in detail the components of the HDI, both in terms of regional differences and for the country as a whole. Each index is measured in fractions from 0 to 1 . The main point of each index is to measure the current situation in the country in comparison with the maximum (desired) and minimum values.

We calculated the Income Index (II) of the population at the regional level on the basis of the gross regional product for the constituent entities of the Russian Federation per capita. To calculate the income index, the following formula 1 is applied:

$$
I I=\frac{\ln (G)-\ln (45000)}{\ln (600000)-\ln (45000)}
$$

where $\mathrm{G}$ - gross regional product per capita at current prices.

Based on this, in the period in 2017-2018, the most economically strong and weak regions can be noted, listed in Table 1 .

The southern regions and national republics are at the bottom of the rating. Industry in these regions is very poorly developed, especially in the Chechen Republic and Ingushetia. The low position in the rating of «depressed» regions is associated with a low standard of living, a level of scientific and technical potential, as well as a share in the national economy. 
Life expectancy index (LEI) was measured based on average life expectancy and used the formula (2):

$$
\text { LEI }=\frac{X-25}{85-25}
$$

where $\mathrm{X}$ - life expectancy in the country at birth.

Table 1. GRP by constituent entities of the Russian Federation (gross value added at current basic prices) for 2017-2018, rubles.

\begin{tabular}{|l|c|c|l|c|}
\hline Region & GRP per capita 2017 & Rang & Region & GRP per capita 2018 \\
\hline Tyumen region & 1651995.90 & 1 & $\begin{array}{l}\text { Tyumen } \\
\text { region }\end{array}$ & 1900322.70 \\
\hline Sakhalin Region & 1536359.90 & 2 & $\begin{array}{l}\text { Sakhalin } \\
\text { Region }\end{array}$ & 1577910.30 \\
\hline $\begin{array}{l}\text { Chukotka } \\
\text { Autonomous Area }\end{array}$ & 1354367.70 & 3 & $\begin{array}{l}\text { Chukotka } \\
\text { Autonomous } \\
\text { Area }\end{array}$ & 1386085.30 \\
\hline Moscow & 1152350.90 & 4 & Moscow & 1263698.00 \\
\hline Magadan Region & 1016642.80 & 5 & $\begin{array}{l}\text { Magadan } \\
\text { Region }\end{array}$ & 1088347.40 \\
\hline $\begin{array}{l}\text { The Republic of } \\
\text { Sakha }\end{array}$ & 897460.40 & 6 & $\begin{array}{l}\text { The Republic } \\
\text { of Sakha }\end{array}$ & 951220.20 \\
\hline Saint Petersburg & 697806.10 & 7 & $\begin{array}{l}\text { Saint } \\
\text { Petersburg }\end{array}$ & 727210.60 \\
\hline Komi Republic & 624774.20 & 9 & $\begin{array}{l}\text { Komi } \\
\text { Republic }\end{array}$ & 679162.60 \\
\hline $\begin{array}{l}\text { Kamchatka } \\
\text { Territory }\end{array}$ & 608083.30 & 10 & $\begin{array}{l}\text { Arkhangelsk } \\
\text { region }\end{array}$ & 640787.50 \\
\hline $\begin{array}{l}\text { Krasnoyarsk } \\
\text { Territory }\end{array}$ & $\begin{array}{l}\text { Republic of } \\
\text { Tatarstan }\end{array}$ & $\begin{array}{l}\text { Republic of } \\
\text { Tatarstan }\end{array}$ & 543522.40 \\
\hline
\end{tabular}

In the Russian Federation, in 2018, life expectancy at birth is 72.91 years, compared to $2017-72.7$ years. The dynamics of life expectancy since 2010 can be observed graphically in Fig. 1.

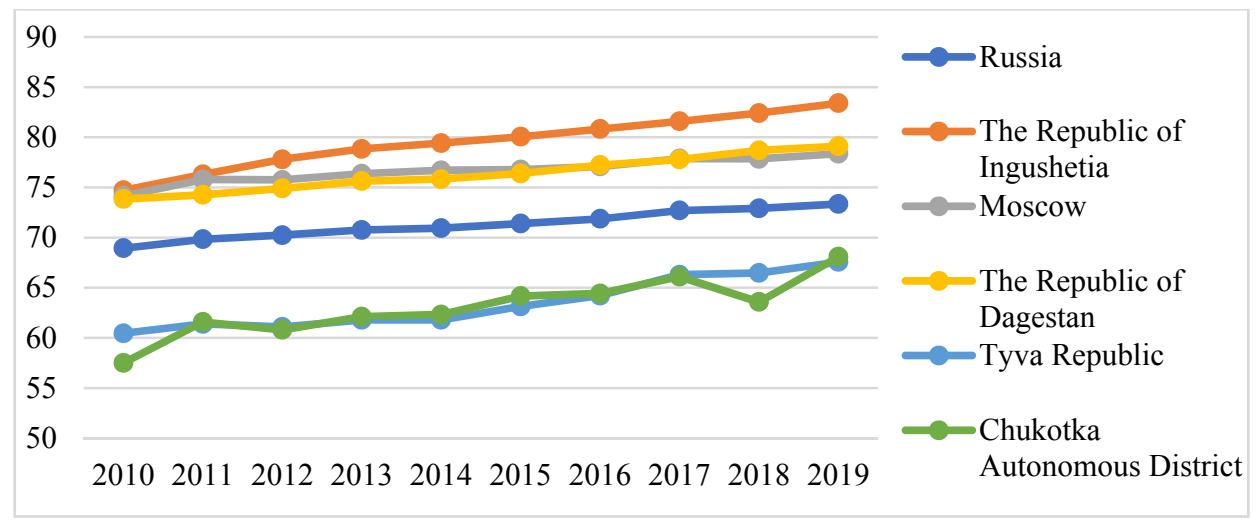

Fig. 1. Life expectancy in the Russian Federation (2010-2019). 
Despite the low level of GRP per capita, according to the results of 2017-2018, the leading region is the Republic of Ingushetia, in which life expectancy exceeded 80 years. The catching-up regions are Moscow, the Republic of Dagestan. However, there are regions where life expectancy has not reached 70 years.

The next step is to calculate the education index. The available statistics, unfortunately, do not allow calculating the index of each constituent entity using the new methodology. The expected duration of study is not estimated for each region of the Russian Federation, therefore, the regional comparison for this index will be considered according to the old methodology applied until 2010.

At the regional level, the education index will be calculated as the sum of the share of the literate population and the share of students among people aged 7 to 24 years. Education coverage is calculated as the ratio of the number of students in educational institutions of all types (general education institutions of primary and secondary education; secondary vocational schools, higher educational institutions of bachelor's, master's and specialist's degrees) to the population aged 7 to 24 years.

Therefore, if all the necessary data are available, we will compose the education index itself, shown in Fig. 2. In general, in Russia in 2018, according to our calculations, the education index is 0.910 .

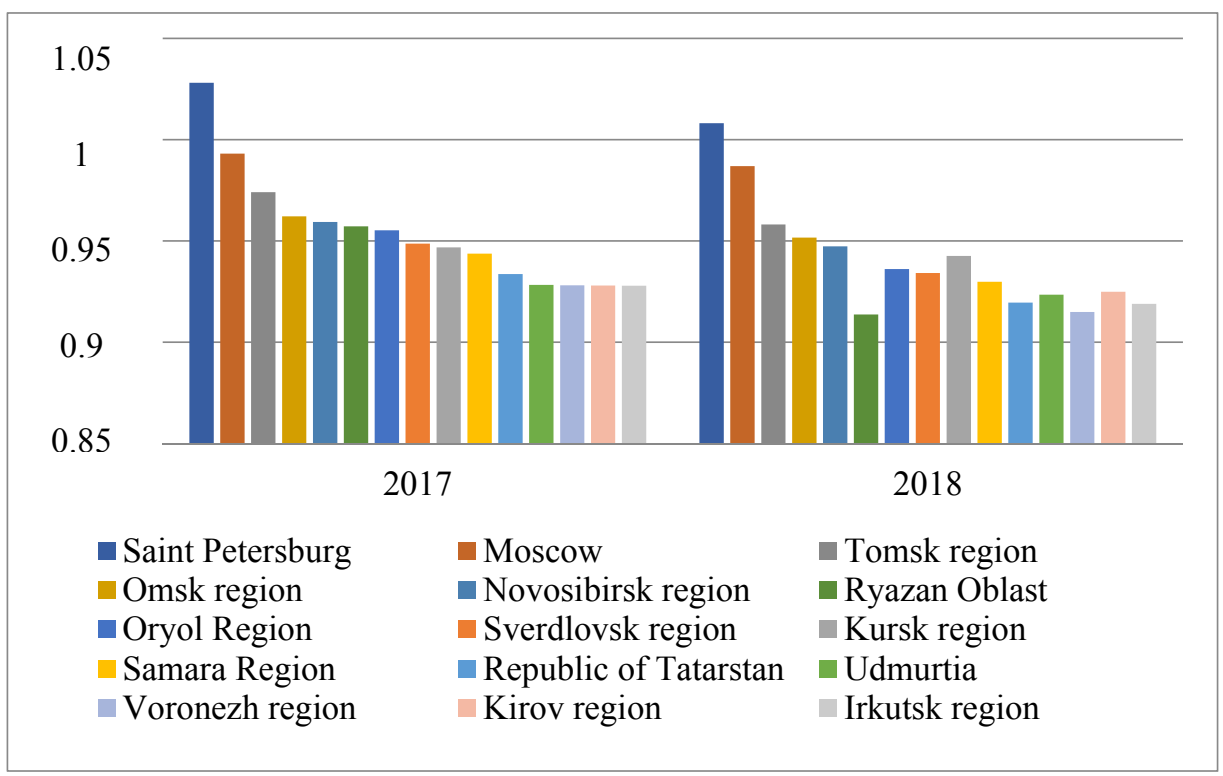

Fig. 2. Education index by regions of the Russian Federationin 2017-2018.

In 2018, the top ten leading regions are headed by St. Petersburg (1.028), Moscow (0.993), Tomsk region (0.939), Tomsk region (0.974), Omsk region (0.962), Novosibirsk region (0.959), Ryazan region (0.957), Orel region (0.955), Sverdlovsk region (0.949), Kursk region (0.947), Samara region (0.944). St. Petersburg and Moscow are leaders in the ranking due to the high proportion of students, as well as due to the leading educational institutions of higher education in Russia, included in the Russian rankings of the top 100 universities in Russia.

The analysis of the HDI constituent components provides us with the opportunity to calculate the human development index itself. The final stage is calculated using the following formula (3) [12]:

$$
H D I=\sqrt[3]{I I * L E I * E I}
$$


where HDI - human development index;

II - income index;

LEI - life expectancy index;

EI - educationindex.

According to UNDP's annual reports, once calculated, countries are ranked in descending order and divided into four groups [12]:

1. very high level (the index value is not less than 0.8 );

2. high level (index value is not less than 0.7 );

3. medium level (index value is not less than 0.55 );

4. low level (index value is below 0.55 ) of human development.

By analogy, the constituent entities of the Russian Federation were ranked in descending order of the HDI values calculated by the authors, and 3 groups of regions were identified: regions with a very high level of human development, a high level of development and a medium level (Table 2).

Table 2. Human development index across Russian regions 2011-2018.

\begin{tabular}{|c|c|c|c|c|c|c|c|c|c|}
\hline \multirow{2}{*}{ Rang } & \multirow{2}{*}{ Region } & \multicolumn{8}{|c|}{ Year } \\
\hline & & 2018 & 2017 & 2016 & 2015 & 2014 & 2013 & 2012 & 2011 \\
\hline & $\begin{array}{l}\text { The Russian } \\
\text { Federation }\end{array}$ & 0.879 & 0.861 & 0.848 & 0.829 & 0.816 & 0.801 & 0.784 & 0.753 \\
\hline & \multicolumn{9}{|c|}{ With a very high level of human development for 2018} \\
\hline 1 & Moscow & 1.041 & 1.024 & 1.012 & 1.001 & 0.990 & 0.976 & 0.974 & 0.945 \\
\hline 2 & Tyumen region & 1.013 & 0.993 & 0.985 & 0.974 & 0.963 & 0.952 & 0.937 & 0.907 \\
\hline 3 & Saint Petersburg & 0.976 & 0.961 & 0.942 & 0.907 & 0.896 & 0.882 & 0.868 & 0.846 \\
\hline 4 & Sakhalin Region & 0.971 & 0.959 & 0.955 & 0.949 & 0.925 & 0.911 & 0.895 & 0.862 \\
\hline 5 & Magadan Region & 0.940 & 0.932 & 0.908 & 0.870 & 0.863 & 0.844 & 0.829 & 0.793 \\
\hline 6 & The Republic of Sakha & 0.936 & 0.923 & 0.901 & 0.880 & 0.857 & 0.847 & 0.833 & 0.801 \\
\hline 7 & $\begin{array}{l}\text { Chukotka } \\
\text { AutonomousArea }\end{array}$ & 0.921 & 0.909 & 0.897 & 0.873 & 0.845 & 0.825 & 0.824 & 0.774 \\
\hline 8 & Republic of Tatarstan & 0.903 & 0.885 & 0.873 & 0.851 & 0.839 & 0.824 & 0.806 & 0.764 \\
\hline 9 & Komi Republic & 0.899 & 0.881 & 0.875 & 0.862 & 0.860 & 0.852 & 0.833 & 0.789 \\
\hline 10 & Krasnoyarsk territory & 0.894 & 0.879 & 0.868 & 0.843 & 0.824 & 0.812 & 0.807 & 0.786 \\
\hline & \multicolumn{9}{|c|}{ With a high level of human development for 2018} \\
\hline 50 & Vladimir region & 0.797 & 0.782 & 0.766 & 0.740 & 0.726 & 0.709 & 0.687 & 0.654 \\
\hline 51 & Tver region & 0.796 & 0.776 & 0.757 & 0.745 & 0.729 & 0.707 & 0.689 & 0.652 \\
\hline 52 & Smolens kregion & 0.795 & 0.777 & 0.766 & 0.753 & 0.744 & 0.720 & 0.696 & 0.661 \\
\hline 53 & Ulyanovsk region & 0.794 & 0.775 & 0.759 & 0.740 & 0.731 & 0.712 & 0.690 & 0.641 \\
\hline 54 & Amur region & 0.794 & 0.791 & 0.787 & 0.759 & 0.742 & 0.740 & 0.734 & 0.692 \\
\hline 55 & Saratov region & 0.794 & 0.780 & 0.767 & 0.747 & 0.732 & 0.712 & 0.690 & 0.660 \\
\hline 56 & Penza region & 0.793 & 0.779 & 0.769 & 0.741 & 0.722 & 0.697 & 0.669 & 0.622 \\
\hline 57 & $\begin{array}{l}\text { TheRepublic of } \\
\text { Mordovia }\end{array}$ & 0.791 & 0.774 & 0.755 & 0.743 & 0.710 & 0.689 & 0.661 & 0.629 \\
\hline 58 & Kirov region & 0.780 & 0.766 & 0.753 & 0.729 & 0.701 & 0.684 & 0.665 & 0.627 \\
\hline 59 & Republic of Mari El & 0.779 & 0.760 & 0.758 & 0.724 & 0.701 & 0.685 & 0.645 & 0.602 \\
\hline & \multicolumn{9}{|c|}{ With a medium level of human development for 2018} \\
\hline 76 & $\begin{array}{l}\text { Karachayevo- } \\
\text { Circassian Republic }\end{array}$ & 0.697 & 0.683 & 0.669 & 0.652 & 0.650 & 0.622 & 0.577 & 0.552 \\
\hline 77 & Republic of Tuva & 0.696 & 0.667 & 0.641 & 0.627 & 0.607 & 0.584 & 0.559 & 0.532 \\
\hline 78 & $\begin{array}{l}\text { Kabardino-Balkarian } \\
\text { Republic }\end{array}$ & 0.695 & 0.685 & 0.652 & 0.646 & 0.627 & 0.618 & 0.575 & 0.536 \\
\hline 79 & Chechen Republic & 0.651 & 0.637 & 0.614 & 0.605 & 0.557 & 0.504 & 0.453 & 0.367 \\
\hline 80 & $\begin{array}{l}\text { The Republic of } \\
\text { Ingushetia }\end{array}$ & 0.635 & 0.619 & 0.615 & 0.609 & 0.588 & 0.539 & 0.427 & 0.242 \\
\hline
\end{tabular}


The HDI calculated by us for 2018 still leaves Moscow - 1.041, Tyumen Region - 1.013, and St. Petersburg -0.976 among the leaders. These are the three leading regions for several years. The Republic of Tatarstan, as in 2017, remained the same and became the eighth in the ranking of regions in terms of human development with a value of 0.903 .

Moscow and the Tyumen region hold leading positions in the index due to the high value of GRP per capita, however, the indicators of the education system, comparable with the general indicators for the country, are at a level comparable to the national one. When calculating the components of the education index, it turned out that St. Petersburg ranks high in the rating due to the high level of education, since the share of students aged 7-24 in the city is much higher than in other regions of the Russian Federation. The main reason for such a high rate is the move of many residents of other regions to St. Petersburg in order to receive education, therefore, with a smaller population than in Moscow, the difference becomes more noticeable.

At the end of 2018, all regions of the Russian Federation, except for the KarachayevoCircassian Republic (0.696), the Republic ofTuva (0.696), the Kabardino-Balkarian Republic (0.695), the Chechen Republic (0.651) and the Republic of Ingushetia (0.635), exceeded the value of 0.7 , which by the old methodology is high.

\section{Conclusion}

From the analysis of the methodology for calculating the HDI by the first method, due to the lack of statistical data of the second method, it is necessary to highlight the existing shortcomings of this method and propose ways to eliminate them. In our opinion, the disadvantages of the method for calculating the human development index by the first method according to the old methodology until 2010 are:

- limited coverage of human development index indicators. This methodology does not include, for example, such factors as the ecological situation, environment, gender inequality in educational institutions or in the field of employment, unemployment, technical development in the country, information and communication technologies, etc;

- an indicator such as GDP, which is a measure of total income in the economy, as well as an indicator of social welfare. GDP is a market indicator, and therefore does not take into account non-market activities in the economy, for example, raising children. Also, GDP does not always correctly take into account the role of services, the production of which plays an increasing role in the economy. So, for example, a significant part of services (medical or educational) is provided by the state, but the amount of government spending poorly reflects the number of services provided and does not imply their effectiveness. GDP does not take into account the relationship between current and future wealth and does not take into account possible development dynamics;

- the GRP per capita indicator, which we use in this paragraph for an independent and more correct calculation of the value of the human development index. The GRP indicator also does not fully reflect the state of the region. This component is a general regional indicator and does not provide information on the situation and standard of living of specific individuals, because it does not reflect average earnings and the level of per capita income of a region or country. Thus, the index focuses only on looking at national (regional) productivity.

- periodic recalculation of statistical data by Federal Statistics Service, which are used to calculate the values of the components of the human development index, as a result of which there is a discrepancy in the values of the index for different periods of time.

However, today, the method of assessing human capital by the method of calculating the human development index, in our opinion, is one of the most successful and not difficult to reproduce, but despite this, it requires additional study to display the most 
reliable picture of this indicator both at the macro level and at the interregional. Therefore, all the identified shortcomings of this index method are the further tasks of our study.

Thus, the methodology for calculating the human development index at the intercountry level used by UNDP, if used for comparison at the regional level, should be adapted to the characteristics of a particular country. An analysis of the HDI dynamics in combination with interregional comparisons will make it possible to objectively assess the role of regions in the development of the country's human capital. The Russian specificity is as follows - GRP per capita turns out to be the most differentiated indicator between regions. Therefore, there is a noticeable difference of several times in terms of GRP per capita between regions that are rich in natural resources, raw materials, and old industrial regions, which have lost their positions in the current economic situation.

\section{Acknowledgments}

The reported study was funded by RFBR, project number 20-010-00655.

\section{References}

1. Human development Report in the Russian Federation for 2016 (ed. S. N. Bobyleva, L. M. Grigoriev, Analytical Center for the Government of the Russian Federation, Moscow, 2016) URL: https://ac.gov.ru/archive/files/publication/a/11068.pdf (last accessed: 25.03.2021)

2. T. V. Malysheva, M. A. Suchkov, S. A. Bashkirtseva, Management of sustainable economic development in the context of digital transformation, Science and business: ways of development, 5 (107), 155-158 (2020)

3. A. I. Shinkevich, A. A. Lubnina, N. M. Chikisheva, L. M. Simonova, E. E. Alenina, B. B. Khrustalev, R. S. Sadykova, R. R. Kharisova, Innovative forms of production organization in the context of high-tech Meso-economic systems sustainable development, International Review of Management and Marketing, 6(2), 219-224 (2016)

4. P. Dasgupta, The idea of sustainable development, Sustain Sci., 2, 5-11 (2007) DOI: 10.1007/s1 1625-007-0024-y

5. A. Di Fabio, J. M. Peiró, Human Capital Sustainability Leadership to Promote Sustainable Development and Healthy Organizations: A New Scale, Sustainability, 10, 2413 (2018) DOI:10.3390/su10072413

6. A. I. Shinkevich, E. L. Vodolazhskaya, J. A. Abutalipova, R. P. Yakunina, F. F. Galimulina, Ch. A. Misbachova, Directions of Development of Human Capital of Innovative Petrochemical Enterprises, Revista San Gregorio, 42, Special edition, 306318 (2020), ISSN 1390-7247, e.ISSN 2528-7907

7. N. M. Baranova, L. V. Sorokin, An impact of human capital on the sustainable economic development, Economic Analysis: Theory and Practice, 16(12), 2224-2237 (2017) DOI: 10.24891/ea.16.12.2224

8. A. I. Romanova, E. V. Ilyina, A. I. Rakhmatullin, Formation and transformation of capital in the market of information services in the regional economy Bulletin of Economics, Law and Sociology, 1, 45-50 (2015)

9. A. Romanova, Possibilities of internationalization in the integration process of the sphere of educational services, Creative economy, 11, 419-430 (2017)

10. I. V. Gilyazutdinova, A. S. Ponikarova, A. I. Romanova, A. I. Rakhmatullin, R. F. Tukhvatullin, T. A. Elokhova, Technique of the analysis and assessment of innovative industrial risks at different stages of innovative activity, International Journal of Economics and Financial Issues, 6, 74-81 (2016) 
11. UNDP. Human Development Report 2019. Beyond income, beyond averages, beyond today: Inequalities in human development in the 21 st century, New York (2019) URL: http:/hdr.undp.org/en/content/human-development-report-2019 (last accessed: 25.03.2021)

12. UNDP. Human Development Report 2016: Human Development for Everyone. New York (2016) URL: http://hdr.undp.org/en/content/human-development-report-2016 (last accessed: 25.03.2021)

13. World Bank. The Human Capital Index 2020 Update: Human Capital in the Time of COVID-19. World Bank, Washington, DC. (C) World Bank (2020) URL: https://openknowledge.worldbank.org/handle/10986/34432 License: CC BY 3.0 IGO (last accessed: 25.03.2021) 